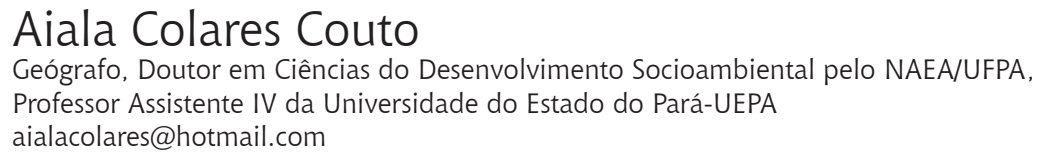

\title{
Conectividade e territórios em rede do narcotráfico na Amazônia Brasileira
}

\begin{abstract}
Resumo
A presença de organizações criminosas que utilizam a região como uma área de trânsito ou rota de distribuição/abastecimento de cocaína de origem Andina demonstra esta relação fronteiriça do crime organizado. Trata-se da construção de territórios, ou mais ainda, representam relações de poder que se manifestam a partir das redes. Este trabalho tem como objetivo analisar a conectividade do narcotráfico na região amazônica a partir da construção de territórios-rede. A metodologia adotada pauta-se em pesquisas bibliográficas e análise de documentos como os relatórios da Delegacia de Repressão ao Crime Organizado (DRCO-PA) e os relatórios de apreensão de entorpecentes da Polícia Federal; ambos os documentos se referem ao período de 2013 a 2015. O resultado da pesquisa aponta para o fato de que o narcotráfico em redes atende ao funcionamento de outras atividades criminosas ao mesmo tempo em que torna vulneráveis as fronteiras do Estado nacional.
\end{abstract}

Palavras-chave: Narcotráfico, Redes, Organização, Território, Amazônia.

\begin{abstract}
CONNECTIVITY AND TERRITORIES IN NETWORKS DRUG TRAFFICKING IN THE BRAZILIAN AMAZON

The presence of criminal organizations that use the region as a traffic area or as a distribution/supply route of Andina origin cocaine, demonstrate this border-ish relation of organized crime. It is about the construction of territories, moreover, represent power relations, which manifest from the networks. This work has as objective to analyze the connectivity of narcotraffic in the amazon region from the construction of territories-network. The adopted methodology bases on bibliographic research and
\end{abstract}


documents analysis such as; reports from the Delegacy of Repression to Organized Crime (DRCO-PA), narcotics apprehension reports from the Federal Police, both documents refer to the period from 2013 to 2015. The research result points to the fact that narcotraffic in networks attends to the functioning of other criminal activities at the same time where they make vulnerable the frontiers of the national state.

Key-words: Narcotraffic, Networks, Organization, Territory, Amazon.

\section{Introdução}

No atual contexto de expansão dos mercados globais, o narcotráfico vem impondo sobre as fronteiras territoriais dos estados nacionais uma lógica perversa de integração, na qual a economia do crime se apresenta como um elemento reestruturador e organizador dos fluxos globais de capitais, pessoas, informações e mercadorias. Desse modo, o crime global do narcotráfico se fortalece, se integrando ao mercado, tornando-se, então, uma atividade altamente lucrativa e problemática em relação aos mecanismos de proteção e segurança pública.

O Brasil, hoje, é o segundo maior mercado consumidor de cocaína do planeta, ficando atrás apenas dos EUA e ficando à frente da Europa, segundo o relatório de 2016 sobre o tráfico global de drogas apresentado pelo Escritório das Nações Unidos Sobre Crime Global (UNODC, 2016). Nesse sentido, facções criminosas como o Comando Vermelho (CV), a Família do Norte (FDN) e o Primeiro Comando da Capital (PCC) vêm estabelecendo redes de articulações regionais, nacionais e globais do tráfico de cocaína, pois é uma estratégia para garantir as conexões que consideram a produção, a circulação e o consumo desse produto.

A organização do narcotráfico depende do controle destas facções do crime organizado e, por isso, o crime organizado constrói bases territoriais que são configuradas espacialmente sobre as cidades e regiões que se tornam espécies de zonas e pontos articulados em redes. E, no Brasil, afirma-se aqui que o narcotráfico se encontra territorializado, impondo uma lógica de sobreposição de poderes, sobreposição esta que é manifestada nas mais diversas formas de violência, as quais caracterizam os conflitos urbanos envolvendo a disputa pelo controle definitivo do território e que envolvem o Estado, além das facções criminosas. 
Diante desse contexto, a Amazônia cumpre um duplo papel para o narcotráfico. Em primeiro lugar, pelo fato de estar localizada geograficamente na fronteira com os países que se destacam pela tradição na produção de cocaína (Bolívia, Colômbia e Peru), a região é uma das portas de entrada da droga (cocaína) que parte em direção aos mercados da Europa e da África, tornando-se estratégica para a organização espacial das atividades ilícitas. Em segundo lugar, a Amazônia é hoje uma das regiões mais importantes para o tráfico de cocaína, pois, além de ser esta a rota primária obrigatória, ela vem servindo de espaço de atuação e expansão de facções do crime organizado e, por isso, o Comando Vermelho (CV), o Primeiro Comando da Capital (PCC) e a Família do Norte (FDN) vêm disputando o controle das rotas da cocaína, a exemplo da rota do rio Solimões que, por enquanto, está controlada pela FDN.

As cidades da região amazônica funcionam para o narcotráfico como pontos de articulação em redes de conectividade do crime global. Esses pontos - ou "nós" - passam a fazer parte de territorialidades em rede ou territórios-rede que ultrapassam os limites fronteiriços do Brasil, representando, desse modo, uma ameaça para os limites territoriais do Estado nacional, destacando que a política nacional de defesa tem o narcotráfico como uma ameaça global.

A hipótese aqui é que na Amazônia o narcotráfico está territorializado em redes (territórios-rede ou territórios em rede) a partir das conexões regionais, nacionais e globais da economia do crime. Configuram-se, assim, relações de poder do narcotráfico, um poder sobreposto ao poder soberano e legítimo do Estado brasileiro.

Para abordar esta temática, divide-se este ensaio em três seções: na primeira seção é realizada uma breve discussão conceitual acerca das categorias rede e território numa perspectiva geográfica. Na segunda, trata-se do narcotráfico enquanto ameaça transfronteiriça para a Amazônia brasileira. Por fim, realiza-se a análise sobre os territórios-rede do narcotráfico na região amazônica, destacando-se a organização reticular dessa atividade ilícita a partir das conexões que envolvem as rotas de transportes e distribuição da droga. 


\section{Territórios-rede e cidades-nós do narcotráfico}

A dimensão espacial do narcotráfico na Amazônia corresponde a um sistema aberto territorializado em redes. Isso ocorre, pois, "as redes constituem a nova morfologia social de nossas sociedades, e a difusão da lógica das redes modifica, de forma substancial, a operação e os resultados dos processos produtivos e de experiência, poder e cultura" (CASTELLS, 1999, p. 497). E as redes "estão presentes em todas as estratégias que os atores desencadeiam para dominar as superfícies e os pontos por meio da gestão e do controle das distâncias" (RAFFESTIN, 1993, p. 200).

As redes destacam-se como elementos importantes que compõem a dinâmica de reestruturação do espaço e, por conseguinte, dos territórios. Nesse sentido, na produção da economia-mundo, elas aparecem como elementos de manutenção das "ordens" e também das "desordens" espaço-territoriais, impostas sobre as diferentes formas de organização social que resultam na sobreposição de poderes, e, consequentemente, de territórios em rede ou territórios-rede, considerando as relações multiescalares: "assim, territorializar-se significa também, hoje, construir e/ou controlar fluxos/redes e criar referências simbólicas num espaço em movimento, no e pelo movimento" (HAESBAERT, 2004, p. 280).

O narcotráfico é uma atividade econômica que tem como uma de suas características a organização em redes para controlar os fluxos. Essa organização cria condições para a territorialização ou territorialidade do crime sobre as regiões ou sobre os Estados nacionais, de forma a se apresentar enquanto uma ameaça geopolítica de caráter transnacional que envolve outras atividades criminosas, como o contrabando de armas e a lavagem de dinheiro, por exemplo.

Quando a referência é a região amazônica, a primeira percepção que se tem é a de uma floresta vulnerável às ações do narcotráfico em função de sua dimensão e proximidade geográfica, as quais permitem um interesse estratégico na articulação, principalmente, do comercio de cocaína em direção aos mercados da África e da Europa e também direcionado para o próprio mercado brasileiro, o qual se destaca enquanto o segundo maior do planeta, atrás apenas dos EUA. 
Segundo Haesbaert e Porto-Gonçalves (2005), verifica-se, do ponto de vista econômico, que o espaço mundial se caracteriza por maior flexibilidade e certa horizontalidade nas relações entre empresas e regiões. Ao mesmo tempo, os processos de globalização, na fase atual de globalização neoliberal, acentuam brutalmente as desigualdades, a exclusão e/ ou segregação socioespacial (com índices crescentes de desemprego) e a exploração (com reintensificação do trabalho escravo, por exemplo). A onda de privatização neoliberal que hoje começa a ser contestada levou a uma mercantilização desenfreada, a qual atinge os mais diferentes domínios da vida humana e inclui a expansão dos circuitos ilegais, como os tráficos de toda ordem, incluindo o tráfico de crianças e órgãos.

Nesse sentido, a conjuntura da globalização dos mercados, a maior fluidez dos capitais por meio da internacionalização do sistema financeiro, a aceleração dos meios de transportes e a revolução das telecomunicações desenharam uma realidade altamente propícia para o avanço acelerado do crime organizado, sobretudo o narcotráfico, que se destaca enquanto uma atividade com extraordinários níveis de rentabilidade.

Segundo o Relatório Mundial Sobre Drogas de 2014, apresentado em Viena pelo Escritório das Nações Sobre Drogas e Crime (UNODC, 2014), aproximadamente 243 milhões de pessoas, o que corresponde a $5 \%$ da população mundial com faixa etária de 15 a 64 anos de idade, já havia usado algum tipo de droga ilícita em 2012. Ainda segundo a UNODC (2014), ocorreu uma queda na disponibilidade global de cocaína em função da queda de sua produção durante o período de 2007 a 2012. Entretanto, o uso de cocaína permanece elevado na América do Norte, mesmo tendo diminuído desde 2006. Além disso, a UNODC também destacou o fato de que, no caso da América do Sul e da África, há um crescimento no uso de cocaína devido à expansão do narcotráfico por esses continentes, assim como o aumento do poder de compra, o qual tornou alguns países asiáticos vulneráveis ao uso da droga.

A ameaça transnacional do tráfico de drogas é, sem dúvida alguma, uma espécie de "inimigo invisível" que coloca em risco a soberania dos Estados nacionais. A característica empreendedora dessa atividade econômica ilícita, ao se fortalecer, consegue ampliar sua escala de atuação em níveis locais, nacionais e internacionais. Nas palavras de Rodrigues (2012, 
p. 7), "a inquietação causada por essa prática proibida é intensa porque ela é apresentada como um inimigo sem rosto, uma força potente e difusa difícil de ser localizada e que se oculta como um animal ardiloso".

Nas últimas décadas, a Geografia tem se preocupado em explicar as diversas manifestações de poderes que constituem territórios, não se restringindo apenas à análise macro dos processos políticos, mas também às diversas formas de construção de territórios a partir daquilo que Foucault (1979) definiu como micropoderes, para explicar o conjunto de relações que constroem o exercício do poder, ou seja, uma micropolítica que também produz territórios.

As redes acompanham o processo de evolução da humanidade, obtendo agora alcance e posição privilegiados no campo das Ciências Sociais. Por isso, o termo adquiriu várias definições e significados. Contudo, na medida em que avança a revolução científica e tecnológica, o termo torna-se mais complexo e adquire novos sentidos. Logo, torna-se imprescindível uma análise dos territórios a partir das redes. Para Santos (1979, p. 139):

O território, hoje, pode ser formado de lugares contíguos e de lugares em rede. São, todavia, os mesmos lugares que formam redes e que formam o espaço banal. São os mesmos lugares, os mesmos pontos, mas contendo simultaneamente funcionalizações diferentes, quiçá divergentes ou opostas.

As concepções de territórios-zona e territórios-rede, apontadas por Haesbaert (2004), podem ser relacionadas diante de uma interpretação empírica com as definições dos conceitos de horizontalidades e verticalidades de Santos (1979, p. 139): "as horizontalidades seriam os domínios da contiguidade daqueles lugares vizinhos, reunidos por uma continuidade territorial; enquanto que as verticalidades seriam formadas por pontos distantes uns dos outros, ligados por todas as formas e processos sociais".

Para Raffestin (1993, p. 204), "a rede faz e desfaz as prisões do espaço, tornando-o território: tanto libera quanto aprisiona. É o porquê de ser o instrumento, por excelência, do poder". A dimensão apresentada aqui por Raffestin (1993) considera as relações de poder que as redes impõem, criando mecanismos de controle e dominação, transformando-se em territórios ou territórios-rede. É dessa forma que o narcotráfico vem se territorializando e se articulando para manter determinados espaços geográficos sob sua influência. 
Os territórios-rede do narcotráfico são redes geográficas, segundo Corrêa (1999, p. 107), "um conjunto de localizações geográficas interconectadas" entre si "por um certo número de ligações". Justamente como ocorre nas formas de organização espacial do narcotráfico, pois cidades tornam-se "nós" pelos quais conectam fluxos de drogas que abastecem os mercados. Assim, as cidades enquanto "nós" de uma rede são importantes para a fluidez da droga. Para Santos (1996, p. 219), "a fluidez não é uma categoria técnica, mas uma entidade sociotécnica. Ela alcançaria as consequências atuais se, ao lado das novas inovações técnicas, não estivessem operando novas formas de ação".

Sobre as redes, "as definições e conceituações se multiplicam, podendo admitir que se enquadre em duas grandes matrizes: a que apenas considera o seu aspecto, a sua realidade material, e uma outra, na qual é também levado em conta o dado social" (SANTOS, 1996, p. 262).

Com isso,

As redes são, pois, ao mesmo tempo, concentradoras e dispersoras, condutoras de forças centrípetas e de forças centrífugas. É comum, aliás, que a mesma matriz funcione em duplo sentido. Os vetores que asseguram à distância a presença de uma grande empresa são, para esta, centrípetos, e, para muitas atividades preexistentes no lugar de seu impacto, agem como fatores centrífugos (SANTOS, 1996, p. 278).

O autor destaca que a "rede global é a forma do espaço", é a fluidez do efeito das reestruturações sobre as fronteiras, a qual é sua principal característica. Assim, o lugar onde a rede organiza sua ação arrumadora do território é um agregado de relações ao mesmo tempo internas e externas. Atuam aqui a contiguidade e a nodosidade; a contiguidade é o plano que integra as relações internas em uma única unidade de espaço, nesse caso, horizontalidade, já a nodosidade é o plano que integra as relações externas com as relações internas da contiguidade, nesse caso, verticalidade. Cada ponto local da superfície terrestre será o resultado desse encontro entrecruzado de horizontalidade e de verticalidade (SANTOS, 1996).

É assim que funciona a organização do narcotráfico através da qual as "cidades-nós" de um conjunto mais amplo de relações verticais fundamentam toda a estrutura da economia do crime sobre o espaço geográfico. Mas, é preciso também considerar que internamente estas relações verticais criam condições para relações mais horizontais a partir de redes sociais que se formam em função da dinâmica social e política 
da economia do crime. Desse modo, as relações de poder do narcotráfico "estão presentes em todas as estratégias desencadeadas pelos atores para dominar as superfícies e os pontos por meio da gestão e do controle das distâncias" (RAFFESTIN, 1993, p. 200).

Para Haesbaert (2004, p. 149), a rede seria o "espaço organizado a partir de relações sociais que priorizam a mobilidade e a fluidez, por meio de linhas ou dutos e polos ou nós (conexões), necessários à dinâmica dos fluxos (materiais ou imateriais) que o fundamenta". Assim, as redes assumem um papel bastante dinâmico no mundo contemporâneo, ou seja, o de enraizar e fixar pontos estratégicos que promovam determinada configuração territorial que demonstre, de alguma forma, o poder que elas detêm, pois:

A estruturação de uma sociedade em rede não é, obrigatoriamente, sinônimo de desterritorialização, pois em geral significa novas territorializações, aquelas em que o elemento fundamental na formação de territórios, a ponto de quase se confundir com eles, é a rede (HAESBAERT, 2004, p. 279).

Decerto, o processo de territorialização do narcotráfico depende da ação das redes. Redes e território se complementam em uma relação que se apoia também na revolução tecnológica presente na globalização contemporânea. Uma lógica organizacional do capitalismo global aproveitada pelo crime organizado, que permite a fluidez de seus fluxos de capitais em forma de lavagem de dinheiro, pessoas, informações e mercadorias (drogas e armas). E, neste início de século, Moreira (2008) vai destacar que uma nova realidade, apoiada não mais nas formas antigas de relações do homem com o espaço e a natureza, mas nas que exprimem os conteúdos novos do mundo globalizado, traz consigo uma enorme renovação nas formas de organização geográfica da sociedade.

Diante desse contexto, "as cidades se convertem em nós de uma trama. Diante de um espaço transformado numa grande rede de nodosidades, a cidade vira um ponto fundamental de tarefa do espaço de integrar lugares cada vez mais articulados em rede". As cidades tornam-se, assim, os nós articulados das redes em constantes movimentos, em fluxos dos mais diversos e que compõem as estruturas sociais resultantes das atividades humanas (MOREIRA, 2008, p. 162).

As cidades que se convertem em nós da trama, definidas aqui como "cidades-nós" do narcotráfico, são aquelas que estão conectadas por meio da 
organização, da comunicação, dos transportes e das informações orientadas pelas redes do narcotráfico em nível local, regional e global, tornando-se a base operacional para a configuração geográfica dos territórios-rede.

As cidades sob a influência das redes do narcotráfico tornam-se redes geográficas:

As redes geográficas são redes sociais espacializadas. São sociais em virtude de serem construções humanas, elaboradas no âmbito de relações sociais de toda ordem, envolvendo poder e cooperação, além daquelas de outras esferas da vida. As redes sociais são historicamente contextualizadas, portanto, mutáveis, das quais são exemplos a rede de parentesco, englobando os membros de uma grande família, ou a de um grupo de pessoas que se organizam em torno de um interesse comum (CORRÊA, 1999, p. 200).

Para Corrêa (1999), a rede se torna geográfica quando nós a consideramos em sua espacialidade. A rede em tela está, de fato, espacializada, mas nem sempre a consideramos sob esse ângulo. Para o autor, a passagem de uma rede social para uma rede geográfica se dá quando assim a consideramos, a despeito de sua necessária espacialidade expressa em localizações qualificadas, e com interações espaciais entre elas. Assim, a rede geográfica só existe mediante estas interações espaciais, as quais surgem como reflexos do conteúdo social que cada localidade promove e que dão sentido ao seu funcionamento e à sua condição de existência enquanto uma rede ou enquanto um conjunto de pontos conectados e espacializados sobre as regiões.

Sendo assim, o narcotráfico forma uma rede social do crime que está presente nas "cidades-nós", uma rede social que se espacializa em determinados recortes dando suporte necessário para a formação de uma rede geográfica. Com efeito, as redes definem determinadas territorialidades e a presença delas se dá pela demonstração do exercício do poder, poder este capaz de transformar as cidades em "nós" de uma rede territorializadora do crime e desterritorializadora do Estado.

\section{0 narcotráfico enquanto uma ameaça fronteiriça}

As fronteiras sempre se destacaram como objeto de preocupação dos Estados nacionais e com a globalização dos mercados a fronteira tornou-se uma categoria analítica de vários trabalhos que tratam de temas 
pertinentes, como: contrabando, biopirataria, tráfico de pessoas e de órgãos, imigração ilegal e narcotráfico. Esses são problemas que desafiam a legitimidade do Estado no controle das atividades consideradas ilegais em seu território.

Para Couto (2014), a fronteira é um espaço complexo o qual não se restringe ao limite estabelecido pelo Estado; ela é palco de tensões e conflitos e, por conseguinte, lugar de encontros e desencontros de reprodução social, política, econômica e cultural. Ela é dinâmica e se constitui enquanto um espaço privilegiado para a expansão dos povos.

A fronteira não foi criada enquanto um conceito jurídico nem, pelo menos, essencialmente, um conceito político ou intelectual. A sua criação foi um fenômeno dos "fatos da vida", a manifestação da tendência espontânea para o crescimento do ecúmeno, esta é origem histórica da fronteira (GEIGER, 1994).

Historicamente, a palavra fronteira implica naquilo que é sugerido etimologicamente, ou seja, a fronteira é o que se encontra "na frente", uma área que foi parte de um todo, especificamente, a parte encontrada na frente. Se a sua teoria for aceita, pode existir (ou devia existir) somente um único Estado - um estado universal. Então, fronteira significa a frente do imperium mundi, expandido em direção dos únicos limites que podem reconhecer, nominalmente, os limites do mundo. Deste modo, a fronteira não é o fim (a cauda), mas o começo (a cabeça) do Estado; é a cabeça irradiada de luz e conhecimento se espalhando no meio da escuridão e do conhecimento (GEIGER, 1994).

Se a fronteira é resultado de um movimento dinâmico que envolve os aspectos políticos, econômicos e culturais da sociedade, em sua essência ela jamais será o limite territorial de um Estado nacional e sim o lugar de encontro dos povos e suas frentes de expansão, por isso, Braudel (1993) irá propor o conceito de "tempo social", através do qual as fronteiras podem ser interpretadas como separatrizes de tempos desiguais ou como evoluções econômicas não paralelas e, ao mesmo tempo, como zonas de integração e articulação do ecúmeno, quanto às regiões avançadas de um país, cuja dinâmica econômica e social possa ser relacionada, seja por progressos tecnológicos, pelas novas formas de organização social ou por ligações com outras formas socioeconômicas. 
Porém, no atual contexto da globalização-regionalização, a fronteira se destaca enquanto um espaço de fluidez de capitais, mercadorias, pessoas e informações num constante movimento de abertura/fechamento ou permissão/controle de determinados fluxos. Ela é um espaço de preocupação dos Estados nacionais, visto que a fronteira se tornou um espaço constantemente observado pelo crime organizado que viabiliza através dela as atividades ilegais, tais como o narcotráfico. Além disso, os avanços tecnológicos do sistema capitalista global, por tornarem cada vez mais fácil a projeção de novas drogas e o acesso à informação por meio da internet, auxiliam o desenvolvimento desta empresa ilícita (SANTANA, 1999).

Por isso, o narcotráfico deve ser considerado uma ameaça transnacional à segurança dos territórios dos países que conectam as ações geoestratégicas dos grupos criminosos, que, ao imporem estratégias de materialização das redes ilegais, criam territórios sobre a organização da economia do crime.

Santana (1999) aponta para o fato de que o principal mercado consumidor para a droga latino-americana são os EUA e, em menor escala, a Europa. Contudo, o narcotráfico não abarca apenas o país fornecedor e o consumidor. Por se tratar de uma atividade ilegal, busca, na verdade, uma diversidade de rotas para que as drogas cheguem ao destino esperado. Com isso, países vizinhos dos produtores e consumidores são inseridos nesta dinâmica, seja na produção da droga, seja em seu tráfico.

Para Santana (1999, p. 101),

O primeiro aspecto global do narcotráfico é a distribuição territorial de suas atividades. Enquanto o cultivo e a colheita das plantas utilizadas como matéria-prima ocorrem em alguns países latino-americanos e asiáticos, as rotas destinadas ao transporte das drogas envolvem outros países e o consumo do produto em si se dá em um terceiro território. 0 tráfico internacional de drogas se mostra estreitamente alinhado ao sistema capitalista global, uma vez que adota a atual Divisão Internacional do Trabalho.

Nesse sentido, a inserção de países e a seleção de mão de obra são essenciais para que a droga obtenha o seu destino final. No caso da América, ressalta-se que o destaque maior está para a produção de cocaína, tendo em vista que os maiores produtores de coca estão localizados na América do Sul - nesse caso, os países Andinos. Em decorrência disso, surgiu a 
necessidade de tornar determinados lugares bases ou "nós" da trama das redes ilegais do tráfico internacional de drogas.

As bases locais são importantes para que toda estas relações viabilizem o comércio de entorpecentes e o avanço tecnológico apresente os instrumentos que deem suporte a toda estrutura organizacional dos mecanismos de funcionamento das redes ilegais.

Pode-se, então, afirmar que o narcotráfico apresenta riscos de diversas naturezas para a soberania dos Estados nacionais, especialmente nos países da América. Ele é um risco em potencial para a ordem jurídica, política e social destes países; sobretudo, em função de os maiores produtores de cocaína (países andinos) e o maior mercado consumidor dessa droga (EUA) estarem localizados neste continente.

Com isso, os respectivos governos enfrentam a ameaça interna e transnacional dos grandes cartéis responsáveis pela produção, pela distribuição e pela territorialização do narcotráfico. O objetivo dos cartéis da droga é extrair lucro das transações comerciais que envolvem o tráfico de drogas e a expansão do comércio global de entorpecentes, que permitiu com que, ao longo do tempo, eles fossem fortalecidos, estendendo relações para outros territórios.

Pode-se, do mesmo modo, buscar compreender a expansão do narcotráfico sobre as fronteiras pelo viés da globalização-fragmentação, pois muitas áreas geográficas precárias, em função da perversidade sistêmica da internacionalização do sistema capitalista, apresentam potencial de materialização da economia do crime.

\footnotetext{
Embora muito antigo em termos históricos, o tráfico de drogas mobiliza hoje um contingente de pessoas e um montante de recursos inéditos na história. Não há país na face da Terra que não esteja, de uma forma ou de outra, articulando na sua teia de poder. As facilidades de deslocamento e transporte no atual período técnico-científico promoveram um incremento substancial nas atividades do chamado "narcotráfico" e sua globalização (HAESBAERT; PORTO-GONÇALVES, 2005, p. 63).
}

A estrutura organizacional do narcotráfico, ao vincular-se às estruturas formais da economia global e à estrutura institucional do Estado, acaba passando despercebida pelas fronteiras, tornando-se um "inimigo invisível". Para Castells (1999), com a globalização, simultaneamente, as atividades criminosas e organizações, ao estilo da máfia de todo o mundo, 
também se tornaram globais e informacionais, propiciando os meios para o encorajamento de hiperatividade mental e desejo proibido, juntamente com toda e qualquer forma de negócio ilícito procurado pelas sociedades, de armas sofisticadas à carne humana.

Arbex Junior (2005) aponta para o fato de que os estudos apresentados por especialistas indicam que grupos mafiosos, tradicionalmente limitados às próprias regiões, começaram a se associar, provavelmente no final dos anos de 1980, com o objetivo de estender sua influência internacional, acompanhando a globalização econômica. A conjuntura da globalização dos mercados, a maior fluidez dos capitais por meio da internacionalização do sistema financeiro, a aceleração dos meios de transporte e a revolução das telecomunicações desenharam uma realidade altamente propícia para o avanço acelerado do narcotráfico, atividade que apresenta extraordinários níveis de rentabilidade.

Nessa conjuntura, quando a referência é o Brasil, a conjunção destes fatores continua a gerar condições propícias para a expansão do narcotráfico, fazendo com que o País deixe de ser apenas uma rota privilegiada do narcotráfico internacional, tal como tradicionalmente se fez acreditar. O Brasil processa, importa e exporta vários tipos de drogas e tornou-se importante centro de produção e consumo, além de fornecer novas drogas alternativas para os mercados interno e externo e de se ter constituído em mais uma peça da engenharia do narcotráfico internacional. Assim, rapidamente cresce a importância do País no comércio internacional de drogas. Aumentam, então, no cenário mundial, as expectativas quanto a seu papel no enfrentamento do mesmo (PROCÓPIO FILHO; VAZ, 1997).

Talvez a maior dificuldade brasileira no combate ao tráfico de drogas esteja na dimensão de sua extensa fronteira. Somado a isso está a localização privilegiada do país para os narcotraficantes, que se encontra próximo aos principais produtores de coca, além da posição geográfica estabelecer a área de trânsito praticamente obrigatória para a distribuição de cocaína em direção à Europa e à África. O Brasil também se caracteriza enquanto um território de refúgio para traficantes em fuga de países vizinhos, fornecendo os principais materiais químicos para o beneficiamento de pasta de base. 
Todavia, é importante compreender a organização espacial e territorial do narcotráfico no Brasil e os mecanismos e estratégias de conexão com os circuitos de produção, distribuição e consumo do mercado de drogas ilícitas que sustentam as redes e os cartéis do crime organizado, atuantes em diversas escalas. A tentativa de compreensão desse processo passa pela análise do contexto da região amazônica, ou seja, a estrutura organizacional do tráfico de drogas na região se apropria de características peculiares que the são concedidas.

Diante disso, a Amazônia brasileira enfrenta um grave problema em suas fronteiras: problemas relacionados às atividades ilícitas. Isso ocorre porque esse papel que o Brasil desempenha para o narcotráfico colocou a região em uma condição de conexão com as redes ilegais do crime organizado presentes em países da Comunidade Andina (Bolívia, Colômbia e Peru) e presentes no próprio território brasileiro (CV, PCC e FDN). A região vive uma situação extremamente complexa, constituída de redes de relações, conflitos e sinergias entre atores locais, nacionais e internacionais, os quais vão para além das fronteiras, envolvendo grandes empresas estatais e privadas (tanto nacionais quanto internacionais), com forte presença do governo federal se comparado aos governos municipal e estadual (MACHADO, 2002).

Os relatórios da UNODC $(2014 ; 2015 ; 2016)$ e da Polícia Federal do Brasil $(2014 ; 2015)$ apontam para a informação de que o narcotráfico, neste início de século, é uma das principais ameaças que o Brasil enfrenta para a manutenção da estabilidade política nas fronteiras da Amazônia. Organizado em redes, cria estruturas de poder que conectam o local e o global nas relações transnacionais do comércio de drogas ilícitas, nas quais as redes "usam" e "abusam" da região, criando novas dinâmicas territoriais a partir de necessidades voltadas para ampliar as atividades operadas de forma ilegal.

Este mundo interconectado estabelece uma instantaneidade das informações e obedece a uma ordem global - a qual se sobrepõe sobre a ordem local - que não seria possível sem a existência das redes técnicas (SANTOS, 1996), as quais dão vida e sentido para a fluidez que o espaço geográfico adquire. A técnica se constitui como um elemento importante para a escolha das cidades pelos narcotraficantes, pois garante os canais de comunicação que promovem toda ordem ou desordem na região amazônica. 
Com efeito, o narcotráfico é um dos principais problemas da Amazônia da Colômbia, da Bolívia e do Peru, sendo também um problema da Amazônia de países como a Venezuela, Equador e, principalmente, da Amazônia brasileira. O Brasil e a região exercem um papel importante para o circuito global das redes, principalmente na faixa de fronteira com os países Andinos (Peru, Bolívia e Colômbia) que se destaca enquanto corredor de entrada dos fluxos de drogas ilícitas. Desse modo, estabelece-se um novo cenário de conflitos na região e de preocupação do governo brasileiro. Portanto, a questão surge como um objeto de preocupação do Estado em relação à defesa do território. São novas dinâmicas territoriais em rede na Amazônia, redes espacialmente organizadas, que não respeitam os limites do território nacional e cujas relações vão além das fronteiras brasileiras.

\section{Territórios-rede do narcotráfico na Amazônia}

Para tratar das questões sobre a organização do narcotráfico na Amazônia brasileira, foi preciso propor uma interpretação a partir das relações de poder presentes na construção de territórios-rede, ou melhor, uma abordagem interpretativa sobre os territórios em rede do narcotráfico, ou seja, formas de conexão entre pontos e linhas a partir da perspectiva do poder; perspectiva essa que promove esta sinergia entre local, regional e global em termos de organização do crime. Nesses termos, o narcotráfico em rede torna-se uma espécie de instituição que não estabelece limites para seu funcionamento, tornando-se, desse modo, uma ameaça constante para os territórios dos Estados nacionais.

O narcotráfico também traça a sua geoestratégia, um tipo de política externa que é guiada pelos fatores geográficos que o potencializam enquanto atividade sob o comando de organizações criminosas. A dinâmica geográfica das regiões potencializa as diferentes etapas de um comércio que envolve a produção, a distribuição e o consumo da droga. Aqui será considerada a cocaína, já que se trata da América do Sul, a partir de uma abordagem que envolve a Amazônia brasileira. Sabe-se, então, que as redes do narcotráfico internacional funcionam atribuindo funcionalidades específicas às regiões que estão sob sua articulação, formando uma 
divisão internacional do trabalho criada a partir da própria necessidade do comércio global de entorpecentes.

Sobre essa divisão internacional do trabalho, para Arbex Junior (2005, p. 24), "em termos bem amplos, por exemplo, a produção de cocaína é principalmente na Amazônia (Colômbia, Bolívia e Peru), a de ópio e derivados na Ásia central (Afeganistão) e as drogas sintéticas nos Estados Unidos e na Europa". É dessa forma que se encontra a divisão internacional do trabalho em relação ao narcotráfico, destacando a importância da região amazônica para o tráfico de cocaína de origem andina. Miyamoto (2009) aponta em qual momento a questão do tráfico de drogas, certamente, tornou-se um dos maiores problemas para os países, não apenas consumidores, mas também aqueles considerados rotas e produtores. O comércio de drogas é visto como o segundo negócio mais rentável do mundo, depois da indústria de armamentos.

Sobre o tráfico de cocaína, para que a droga possa chegar aos principais mercados consumidores do mundo, as redes constroem estruturas modais, as quais passam a fazer parte de um conjunto de fluxos que obedecem a uma ordem muitas vezes externa ao território, mas que internamente necessita formar uma base operacional para dar conta de controlar a fluidez que abastece toda a organização espacial do "mercado da droga". As redes, então territorializadas, materializam toda a estrutura organizacional que permite o movimento local, regional e global do tráfico de cocaína no mundo.

É neste cenário que a Amazônia brasileira torna-se importante para as redes do narcotráfico, pois seus rios ultrapassam os limites fronteiriços do Estado, além de possuir uma floresta densa, latifoliada, com mata fechada e com imensos vazios demográficos. Essas particularidades, somadas à proximidade junto aos maiores produtores de cocaína do mundo, aliadas, também, à atuação precária do Estado, permitiram a inserção da região no contexto regional-global do narcotráfico com impactos sobre as cidades amazônicas, como Manaus, Tabatinga e Tefé, no estado do Amazonas, além de Altamira, Belém e Santarém, no Pará, que representam importantes nós das redes do narcotráfico territorializadas sobre a região.

Machado (1998) lembra que pesquisas anteriores já sugeriam que nas últimas décadas as redes do narcotráfico obtiveram relativo sucesso 
em fazer uso da bacia amazônica sul-americana, como unidade funcional e como região geográfica, como as firmas e os empreendimentos que exploraram o comércio ilegal de drogas e o contrabando de mercadorias.

Para implantar e administrar suas operações, além de diminuir os riscos de apreensão da droga e de intervenção por parte dos órgãos de segurança pública, os empreendimentos ilegais necessitam criar "canais de comunicação" entre os diferentes níveis de organização territorial, gerando uma tensão entre lógicas diferenciadas que devem ser levadas em conta:

As redes encontram outras lógicas, ancoradas no solo. Podem adaptar-se mais ou menos facilmente às cidades ou aos países, à inércia do semiurbano ou à rigidez das malhas agrícolas. No entanto, existe uma instabilidade e uma tensão entre as redes e o território, entre o dinâmico e o estático, entre aquilo que circula e aquilo que habita (MACHADO, 1996, p. 23).

Os corredores das drogas na Amazônia funcionam como "arcos" conectados aos "pontos" ou "nós", formando redes geográficas. De acordo com Machado (1996), os corredores são as grandes linhas de circulação que marcam a direção geral de trânsito até a plataforma de exportação ou o mercado final de destino. Um corredor, no entanto, comporta inúmeras rotas. A escolha da rota depende de arranjos pretéritos no terreno, com forças de segurança e apoio local e de combinação de meios de transportes utilizados.

Com a expansão do tráfico de cocaína no Brasil a Amazônia tornou-se uma rota primária de distribuição da droga em direção à Europa e à África, e aos mercados do Sudeste brasileiro, através do contato com os países da Comunidade Andina, Guianas e Suriname. Todavia, deve-se ressaltar o destaque das regiões Sul e Sudeste, neste caso como rotas secundárias da cocaína, visto que o Sudeste aparece como o grande mercado consumidor interno; além disso, há de se destacar a região Nordeste, que aparece como rota secundária da cocaína em direção à Europa, rota esta conectada diretamente com a Amazônia. Contudo,

a cocaína também pode entrar nas regiões Sul e Sudeste do Brasil pela Bolívia e pelo Chile, atravessando a região Centro-Oeste, porém, neste caso específico, apresentando um maior risco de apreensão nas fronteiras brasileiras, por outro lado levando diretamente a droga para ser beneficiada no Sudeste, onde será consumida ou exportada. Ressalta-se que o Brasil foi incorporado ao sistema ilegal do cartel 
de Medellín ainda em meados da década de 1980, sendo utilizado como rota de trânsito. A partir de 1989, com a invasão do Panamá, tropas norte-americanas passaram a controlar de forma mais efetiva o espaço aéreo do Caribe. Em decorrência disso, as grandes organizações de tráfico de drogas colombianas foram obrigadas a buscar outras plataformas de exportação (STEIMAN, 1995, p. 20).

De fato, há uma necessidade de dominação político-econômica do narcotráfico. Tem-se, então, uma dominação de "fora para dentro", conectada de "dentro para fora", que manifesta as relações de poder, as quais, por meio de cidades-nós na região, configuram os territórios-rede ou territórios em rede e seus fluxos, os quais ultrapassam os limites territoriais do Estado.

Para Souza (1995, p. 94), o território-rede representa uma "ponte conceitual" que reúne a contiguidade espacial do território "no sentido usual" e a descontinuidade das redes, formando-se, assim, um território descontínuo que, dependendo da escala, é "uma rede a articular dois ou mais territórios contínuos", como no caso dos territórios-rede de diferentes facções do narcotráfico, estruturando de forma descontínua seu poder por intermédio da conexão entre várias favelas em disputa no município do Rio de Janeiro.

Na Amazônia, o narcotráfico em rede transformou algumas cidades da região, como as apontadas aqui neste texto (Belém e Manaus, por exemplo), em "nós" da interação espacial, e a existência desta interação se dá por via de "[...] conexões com o exterior, que às vezes são até mesmo privilegiadas em relação às conexões internas, representam processos concomitantes de desterritorialização, ou seja, neste caso, de perda de controle do Estado em relação às dinâmicas internas ao território nacional" (HAESBAERT, 2004, p. 294).

De acordo com Bonnemaison (1981, p. 253-254 apud HAESBAERT, 2004, p. 280), "um território, antes de ser uma fronteira, é primeiro um conjunto de lugares hierarquizados, conectados a uma rede de itinerários. A territorialização engloba, ao mesmo tempo, aquilo que é fixação [enraizamento] e aquilo que é mobilidade; em outras palavras: tanto os itinerários quanto os lugares".

$\mathrm{Na}$ formação do território-rede do narcotráfico na Amazônia, o controle ou a influência sobre a área estão, muitas vezes, distantes do ponto de vista físico, mas muito mais próximos do ponto de vista 
relativo, às vezes muito mais próximos do que o próprio aparelho do Estado, logo, é dessa forma que as cidades da região tornam-se pontos ou nós das redes; redes que em funcionamento impõem suas lógicas de controle e de relações de poder, as quais fazem parte de uma trama que envolve os Cartéis colombianos, por exemplo, e o crime organizado do Brasil, cujas facções, necessariamente, utilizam a Amazônia como rota primária.

Assim, é importante destacar a análise de Haesbaert (2004, p. 281), pois,

se o território hoje, mais do que nunca, é também movimento, ritmo, fluxo, rede, não se trata de um movimento qualquer, ou de um movimento de feições meramente funcionais: ele é também um movimento dotado de significado, de expressividade, isto é, que tem um significado determinado para quem o constrói e/ou para quem dele usufrui.

A rede legal do Estado se "ausenta" ou se ausentou por muito tempo, ou ainda atua de forma precária, deixando lacunas que são preenchidas por atividades ilegais.

O mapa 1 apresenta a organização em rede do narcotráfico na Amazônia brasileira e demonstra a conexão que envolve várias cidades da região. Podemos, então, visualizar várias rotas que partem da Bolívia, da Colômbia e do Peru, nas quais uma área integra a Bolívia com o Brasil, através das rotas pelos estados de Rondônia e Mato Grosso com destino ao Centro-Oeste e Sudeste; a outra rota parte do Peru em direção ao estado do Amazonas, seguindo para o estado do Pará e Maranhão, com destinos para o Nordeste, Sudeste, Europa e África; por fim, a rede de integração do narcotráfico que parte da Colômbia na Calha Norte da Amazônia e integra o Amazonas e o estado de Roraima. Destaca-se, também, a importância da bacia Amazônia para a articulação das redes e os territórios-rede do narcotráfico sobrepostos ao território legítimo do Estado brasileiro. 


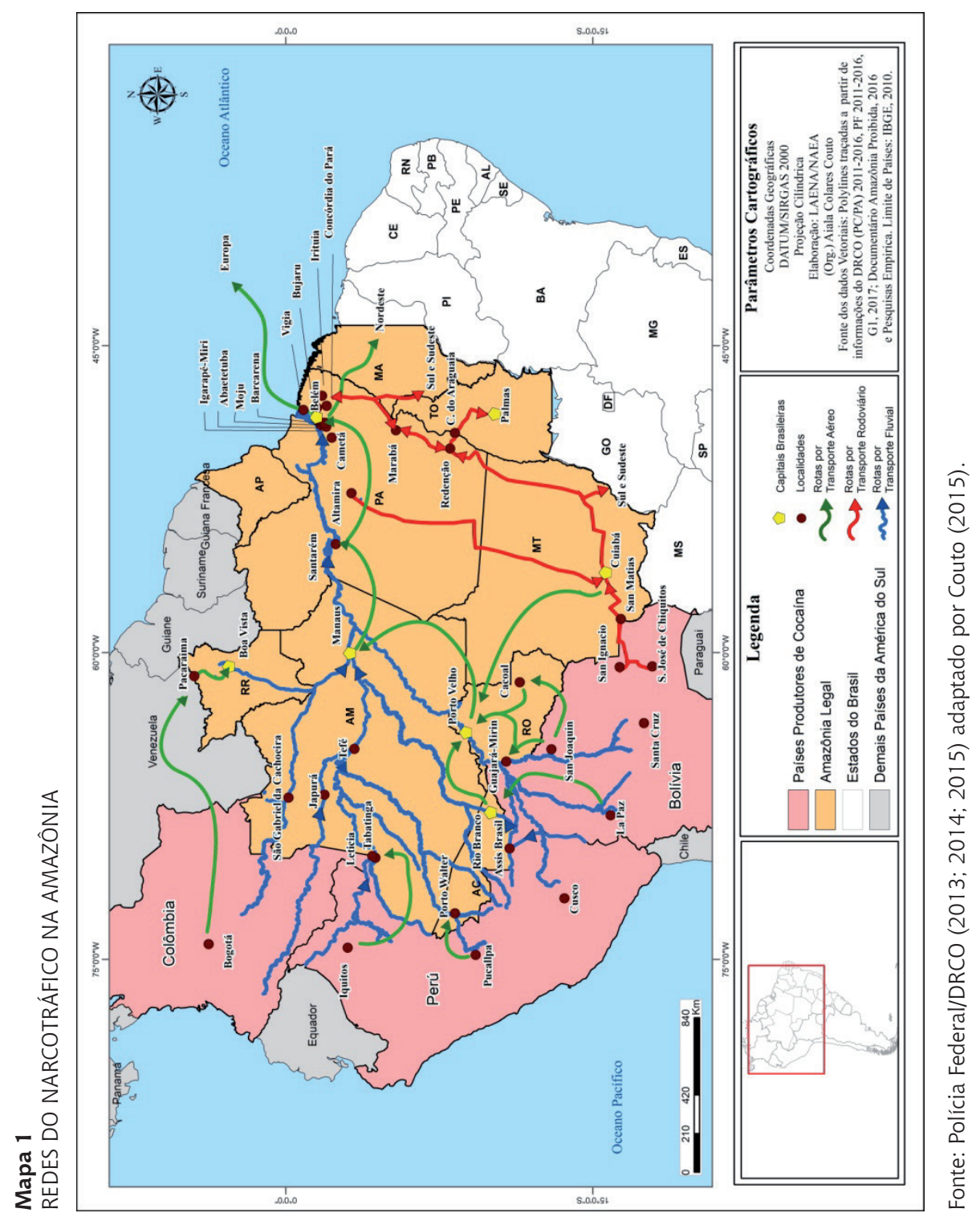

142. GeoTextos, vol. 15 , n. 2 , dezembro 2019. A. Couto. 123-147 
A conectividade das redes do narcotráfico é desenhada a partir dos objetivos das organizações criminosas que são responsáveis pela criação de uma Geografia do crime. Portanto, quando tratamos da incorporação das cidades nessa lógica organizacional - e isso significa o modelo estrutural que conecta as redes - elas obedecem a uma concepção teleológica, pois os lugares são selecionados conforme os interesses da rede. Nessa conjuntura, as redes do narcotráfico selecionam sujeitos e lugares específicos para sua organização.

Pode-se dizer, desse modo, que a conectividade das redes ilegais do narcotráfico materializa-se em territórios-rede com suas manifestações de poder, as quais se sobrepõem às forças política e jurídica do Estado. Com efeito, o narcotráfico promove uma fragilidade institucional no âmbito da segurança e da defesa das fronteiras da Amazônia e isso faz com que ele se enquadre na categoria de ameaça transfronteiriça. Uma ameaça que opera a partir de circuitos espaciais que têm nas cidades seus pontos ou "nós" em uma escala de ação/de poder que se constitui enquanto base para a organização dos territórios controlados pelo crime organizado.

\section{Considerações finais}

Os estudos sobre a atuação do crime organizado na Amazônia brasileira pouco ou nenhuma importância têm dado aos territórios-rede ou territórios em rede do narcotráfico e seus efeitos sobre a região. Assim, a Geografia tem a responsabilidade de provocar um debate reflexivo e apresentar uma discussão coerente acerca das perspectivas de organização do narcotráfico sobre a região a partir das cidades-nós. O narcotráfico territorializado difunde suas relações de poder que negligenciam e se sobrepõem à clássica visão de território do Estado e seu discurso de soberania nacional e política.

O destaque que as redes ilegais do narcotráfico atribuem à região amazônica tornou-a a rota primária ou área de trânsito obrigatório para o transporte da droga (cocaína) realizada por narcotraficantes dos países da Comunidade Andina (Bolívia, Colômbia e Peru) conectados às facções criminosas do Brasil, tais como: Comando Vermelho (CV), Primeiro Comando da Capital (PCC) e Família do Norte (FDN). A região apresenta 
rotas estratégicas de distribuição de cocaína em direção aos mercados da África, da Europa e do Sul e do Sudeste brasileiros; o narcotráfico, portanto, é uma atividade conectada ao mercado global e ao mercado regional-nacional que molda seus circuitos espaciais de distribuição e consumo da droga.

As fronteiras da região amazônica tornaram-se desprotegidas diante das ações do narcotráfico em rede. Elas são espaços vulneráveis e instáveis devido à presença do crime organizado, facilitada pela presença precária do Estado. Esta precariedade alimenta também outras atividades ilegais, a exemplo do tráfico de armas, do contrabando, da biopirataria e da lavagem de dinheiro. A movimentação dos fluxos de droga constitui, desse modo, o resultado dos territórios-rede presentes na Amazônia. Ou seja, as cidades da região estão integradas em uma rede de articulações.

Por fim, é preciso criar estratégias de cooperação entre os países da Amazônia internacional com o intuito de formular intervenções em zonas de fronteiras, voltadas para a construção da cidadania; porém, é fundamental respeitar as especificidades de cada lugar, considerando a diversidade existente nas relações sociais em uma região múltipla, complexa e dinâmica como a Amazônia. A fragilidade ou a precariedade das ações do Estado aos poucos permite esta territorialidade em rede que se materializa e se manifesta na região ao reestruturar e atribuir funções às cidades. Cabe ao Estado, portanto, elaborar políticas públicas que impeçam o fortalecimento do narcotráfico em seu território.

\section{Referências}

ARBEX JUNIOR, José. Narcotráfico, um jogo de poder nas Américas. 5. ed. São Paulo: Moderna, 2005. 95 p.

BRAUDEL, Fernand. Escritos sobre a História. 3. ed. São Paulo: Perspectiva, 1993. 289 p.

CASTELLS, Manuel. A sociedade em rede. v. 1. São Paulo: Paz e Terra, 1999. $698 \mathrm{p}$. 
CORRÊA, Roberto Lobato. Dimensões de Análise das Redes Geográficas. In: CORRÊA, Roberto Lobato. Trajetórias Geográficas. 6. ed. Rio de Janeiro: Bertrand-Brasil, 1999. p. 107-118.

. As Redes Geográficas: cinco pontos para discussão. In: VASCONCELOS, Pedro de Almeida; SILVA, Sylvio Bandeira de Mello e (Org.). Novos Estudos de geografia urbana. Salvador: Universidade Federal da Bahia, 1999. p. 65-70.

COUTO, A. A geografia do crime na metrópole: das redes ilegais à “territorialização perversa” na periferia de Belém. Belém. Eduepa, 2014. 207 p.

DIAS, Leila. Redes: emergência e organização. In: CASTRO, Iná Elias; GOMES, Paulo Cesar da Costa; CORRÊA, Roberto Lobato (Org.). Geografia: conceitos e temas. 12. ed. Rio de janeiro. Bertrand Brasil, 1995. p. 15-64.

FOUCAULT, Michel. Microfísica do poder. Rio de Janeiro: Graal, 1979. 431 p.

GEIGER, Pedro Pinchas. Regiões fronteira no Brasil. Anuário IGEO, Rio de Janeiro, v. 17, p. 53-64, 1994. Disponível em: <http://www.ppegeo.igc.usp.br/ index.php/anigeo/article/view/1723/1612>. Acesso em: 21 ago. 2010.

HAESBAERT, Rogério. $\mathbf{O}$ mito da desterritorialização: do fim dos territórios à multiterritorialidade. 3. ed. Rio de Janeiro: Bertrand Brasil, 2004. 400 p.

; GONÇALVES, Carlos Walter Porto. A nova des-ordem Mundial. São Paulo: UNESP, 2005. 160 p.

MACHADO. Lia Osório. O comércio ilícito de drogas e a geografia da integração financeira: uma simbiose? In: CASTRO, Iná; GOMES, Paulo Cesar; CORRÊA, Roberto Lobato (Org.). Brasil: questões atuais da reorganização do território. 6. ed. Rio de Janeiro: Bertrand Brasil, 1996. p. 15-64.

. Notas sobre o complexo coca: cocaína na Amazônia sul: Americana. In:

Relatório CNPQ; FINEP. [S.I.]: [s.n.], 1998.

Região, Cidades e Redes Ilegais. Geografias Alternativas na Amazônia Sul-americana. In: GONÇALVES, Maria Flora; BRANDÃO, Carlos (Org.). Regiões e cidades: cidades nas regiões. São Paulo: UNESP, 2002. p. 695-707.

MIYAMOTO, Shyguenoli. Amazônia, política e defesa. In: NASCIMENTO, Durbens Martins (Org.). Relações internacionais defesa na Amazônia. Belém: NAEA; UFPA, 2009. p. 45-59.

MOREIRA, Ruy. Da região à rede e ao lugar: a nova realidade e o olhar geográfico sobre o mundo. Rio de Janeiro: Contexto, 2008. 191 p.

PARÁ. Relatório de gestão superintendência regional da Polícia Federal no

Pará. Exercício. Belém, 2013. 
Relatório de gestão superintendência regional da Polícia Federal no Pará. Exercício. Belém, 2014.

Relatório de gestão superintendência regional da Polícia Federal no Pará. Exercício. Belém, 2015.

PARÁ. Relatório de apreensão de entorpecentes no Pará da Divisão de Repressão ao Crime Organizado da Polícia Civil. Belém, 2013.

Relatório de apreensão de entorpecentes no Pará da Divisão de Repressão ao Crime Organizado da Polícia Civil. Belém, 2014.

Relatório de apreensão de entorpecentes no Pará da Divisão de Repressão ao Crime Organizado da Polícia Civil. Belém, 2015.

PROCÓPIO FILHO, Argemiro; VAZ, Alcides Costa. O Brasil no contexto do narcotráfico Internacional. Rev. Bras. Polít. Internacional, v. 40, n., p. 78. [1997].

PROCÓPIO FILHO, Argemiro. Drogas ilícitas em espaços transfronteiriços. Revista Cena Internacional, v. 2, n. 1, p. 92-122, 2000.

RAFFESTIN, Claude. Por uma geografia do poder. São Paulo: Ática, 1993. $269 \mathrm{p}$.

RODRIGUES, Thiago. Narcotráfico: uma guerra na guerra. 3. ed. São Paulo. Desatino, 2004. 123 p.

A infindável guerra norte-americana: Brasil, EUA e o narcotráfico no continente. São Paulo em Perspectiva, v. 2, n. 16, p. 102-111, 2012.

SANTANA, Adalberto. A globalização do narcotráfico. Revista Brasileira de Política Internacional, n. 42, v. 2, p. 99-116, 1999.

SANTOS, Milton. Da totalidade ao lugar. 3. ed. São Paulo: Edusp, 1979. 176 p.

Por uma geografia nova. 11. ed. São Paulo: Hucitec, 1996. 260 p.

SOUZA, Marcelo Lopes de. O território: sobre espaço e poder, autonomia e desenvolvimento. In: CASTRO, Iná; GOMES, Paulo C, C.; CORRÊA, Roberto L. Geografia: conceito e temas. 11. ed . Rio de Janeiro: Bertrand Brasil, 1995. p. 77-116.

STEIMAN, Rebeca. O mapa da droga. 1995. 75f. (Monografia de Conclusão de Curso em Geografia) - Instituto de Geociências, Universidade Federal do Rio de Janeiro, Rio de Janeiro, 1995.

UNODC. O relatório mundial sobre drogas. Washington: UNODC, 2014. Disponível em: <https://www.unodc.org/lpo-brazil/pt/ 
frontpage/2014/01/13-new-unodccampaign-raises-consumer-awareness-oflinks-between-organized-crime-and-250billion-a-year-counterfeit-business. html>. Acesso em: 21 set. 2015.

O relatório mundial sobre drogas. Washington: UNODC, 2015. Disponível em: < http:// www.unodc.org/ documents/ wdr2015/ World_Drug_ Report_2015.pdf. >. Acesso em: 11 set. 2016.

O relatório mundial sobre drogas. Washington: UNODC, 2016. Disponivel em: <https://www.unodc.org/doc/ wdr2016/WORLD_DRUG REPORT_2016_web.pdf>. Acesso em: 15 out. 2017.

Recebido em: 09/10/2019 Aceito em: 10/11/2019 